actions, for example through legislation and security measures, have contributed to a sharp decline in child deaths in tractor accidents.

\section{P72 THE ROLE OF SCHOOL EXPERIENCE IN MEDIATING THE ASSOCIATION BETWEEN CONDUCT PROBLEMS TRAJECTORIES AND NOT BEING IN EDUCATION, EMPLOYMENT OR TRAINING (NEET STATUS) AT AGE 20}

LB Bevilacqua*, RV Viner, BDS De Stavola. GOS Institute of Child Health, University College London, London, UK

\subsection{6/bmjpo-2019-RCPCH-SAHM.73}

Previous research has shown that children and adolescents on different CP trajectories are exposed to a higher risk of being not in education employment or training (NEET) in young adulthood/adulthood. However, there has not been much research on factors that may mediate the association between CP trajectories and NEET status at age 20. In the present study, we investigated the role of school experience at age 14 years in mediating the association between CP trajectory group defined from age 4 to 13, namely Early-Onset Persistent (EOP), Adolescent-Onset (AO) and Childhood-Limited (CL), and Low (L) and NEET status at age 20. Using G-computation, we estimated the natural direct and indirect effects of CP trajectory group on NEET using data from ALSPAC. We found that school experience mediates the relationship between EOP trajectory and NEET status at age 20. The impact of attrition on these results was also investigated via imputation of missing values under the assumption of missing at random. These findings highlight the role of schools in potentially minimising the risk of becoming NEET in high-risk youth.

\section{P73 'THE MIND BUBBLE'- A PATIENT EMPOWERMENT TOOL}

K Parker*, I Smyth, S Shah, S Millar. Children and Young Persons Diabetes Service Southern Health and Social Care Trust, Belfast, UK

\subsection{6/bmjpo-2019-RCPCH-SAHM.74}

Aims Empower our young people and encourage self-management and advocacy -that remains the overarching principle at our diabetes clinic. A key component of this is to understand the expectations of young people and answer questions they seek answers to. By using their checklist and not our own, we may cover fewer items but are more likely to have a purposeful and eventually fruitful conversation. Our aim was to identify each patient" individual goals and tailor discussions accordingly.

Methods We distributed questionnaires, in the form of a 'mind bubble', to young people over 12 years attending paediatric diabetes clinics in our hospital over a two-month period. A 'mind bubble' is a simplified visual questionnaire designed to be user-friendly and engage with young people. Young people were asked 'What would you like to discuss today at your diabetes clinic?' and their responses were then addressed at that attendance.

Results We received 32 completed 'mind bubbles'. The most common response was for advice on hyperglycemia and hypoglycaemia management (44\%). 7 responses (22\%) were regarding practical advice on holidays and exercise, 6 responses
(19\%) for specific questions regarding insulin pumps and infusion sets, and 3 (9\%) regarding the use of associated computer programmes. 3 responses (9\%) asked for education on ketones. Feedback from these were very positive specially from parents who felt their young person was empowered to articulate exactly what they wanted from us.

Conclusions The 'mind bubble' provides a practical way for young people to inform the diabetes team of their expectations for each clinic visit. The wide variety of responses highlights the challenges of engaging with young people with complex, life long conditions, and the need for patient centred care to enable our young people grow in confidence.

\section{P74 'EDUCATION FOR ALL' IN THE ERA OF SDGS? ADOLESCENTS IN SCHOOLS IN BISSAU, GUINEA-BISSAU}

${ }^{1} \mathrm{G}$ Gunnlaugsson*, ${ }^{1} \mathrm{FN}$ Baboudóttir, ${ }^{2} \mathrm{~A}$ Baldé, ${ }^{3} \mathrm{Z}$ Jandi, ${ }^{1,3} \mathrm{H}$ Boiro, ${ }^{3} \mathrm{JR}$ Butiam Có, 1J Einarsdóttir. 'Sociology, Anthropology, and Folkloristics, University of Iceland, Reykjavik, Iceland; ${ }^{2}$ Health Sciences, Jean Piaget University Guinea-Bissau, Bissau, Guinea-Bissa;

${ }^{3}$ Social Sciences, Institute of Education and Research (INEP), Bissau, Guinea-Bissau

\subsection{6/bmjpo-2019-RCPCH-SAHM.75}

Aims Following the adoption of the Sustainable Development Goals (SDGs) 2016-2030, the health and wellbeing of adolescents are in focus for global health policy. Comprehensive investment in adolescents' health and wellbeing, including education, is estimated to generate high economic and social returns, in particular in resource-poor countries. Here the aim was to identify socio-economic determinants for school attending Bissau-Guinean adolescents aged 14-19 years.

Methods In June 2017, a survey with locally adapted and pilot tested Planet Youth questionnaire was conducted in the capital Bissau. School classes in 16 schools, both public and private, were weighted by size and randomly selected from a special registry of 114 classes with 4.470 students aged 14-19 years.

Results In total, 2,039 students completed the questionnaire (52\% girls), and 52\% attended public schools. The mean age of girls was 16,3 years compared to 16,4 years (median 17) for boys; girls were 1.29 times (95\% CI 1.08-1.55) more likely to attend a private school compared to boys. Adolescents from better-off families were 2.10 times (95\% CI 1.492.95) more likely to attend private school compared to those worse off. Further, those who reported speaking Portuguese (official language) in their homes were 4.13 times (95\% CI 2.65-6.44) more likely to attend a private school compared to participants speaking other languages, including the lingua franca Creole. There was no statistically significant difference between adolescents in the two types of schools to report absence from school because of illness during the last months before the survey. Nonetheless, participants in public schools were 2.22 times (95\% CI 1.64-2.99) more likely to skip classes one or more days in the same period compared to participants in private schools.

Conclusions In a setting of political instability, and socioeconomic hardship, better-off parents choose private schools to give their children better educational opportunities than are on offer in public schools that are frequently on strike. The Bissau-Guinean 'SDG generation' needs support through better public school infrastructure and staff to improve their educational opportunities and thereby allow them to attain their full potential as adults. 